Letters to the Editor

\title{
Dienophilic Reagent for Precolumn Derivatization of 7-Dehydrocholesterol in High Performance Liquid Chromatography1
}

\author{
Kazutake SHIMADA and Tomoyuki OE \\ Faculty of Pharmaceutical Sciences, Kanazawa University, Takara-machi, Kanazawa 920, Japan
}

\begin{abstract}
Keywords High performance liquid chromatography, ultraviolet detection, fluorescence detection, precolumn derivatization reagent, dienophile, 4-(1-pyrenyl)-1,2,4-triazoline-3,5-dione, 7-dehydrocholesterol
\end{abstract}

Over the last decades, interest in the metabolism and physiological action of vitamin $\mathrm{D}_{3}\left(\mathrm{VD}_{3}\right)$ has increased exponentially. This compound is metabolized to 25 hydroxy- $\mathrm{VD}_{3}$ in the liver and then to 1,25-dihydroxy$\mathrm{VD}_{3}$ in the kidney to produce biological activity. ${ }^{2}$ It is well known that the 7-dehydrocholesterol (7-DHC) present in the skin is converted into $\mathrm{VD}_{3}$ via pre- $\mathrm{VD}_{3}{ }^{3}$ Much interest has recently been focused on the correlation between age and the 7-DHC concentration level in human skin. ${ }^{4}$ Iwata et al. ${ }^{5,6}$ converted 7-DHC into the fluorescent derivative by a reaction with $3,4-$ dihydro-6,7-dimethoxy-4-methyl-3-oxo-quinoxaline-2carbonyl azide; the determination was made by high performance liquid chromatography (HPLC). This method is sufficiently sensitive for this purpose, though it takes $60 \mathrm{~min}$ at $120^{\circ} \mathrm{C}$ to convert the alcohol into the desired urethane derivative.

The present paper deals with the preparation of a sensitive, highly reactive reagent having a pyrene moiety as a chromophore or fluorophore and a triazolinedione as a reacting group toward the diene moiety, and its applicability to the derivatization of 7DHC for HPLC.

\section{Experimental}

\section{Chemicals}

Pyrene-1-carboxaldehyde and carbazic acid ethyl ester were obtained from Wako Pure Chemical Co. (Osaka, Japan) and Tokyo Kasei Co. (Tokyo, Japan), respectively. Other chemicals used were also commercially available and of reagent grade.

\section{Apparatus}

Proton nuclear magnetic resonance (' $\mathrm{H}-\mathrm{NMR})$ spectra were obtained with a JEOL JNM-FX $100 \mathrm{~S}$ spectrometer (JEOL Co., Tokyo) at $100 \mathrm{MHz}$ using tetramethylsilane as an internal standard. The abbreviations used are $\mathrm{s}=$ singlet, $\mathrm{t}=$ triplet, $\mathrm{q}=$ quartet, $\mathrm{dd}=$ doublet of doublets, $\mathrm{m}=$ multiplet and $\mathrm{br}=$ broad. Mass spectra
(MS) were measured on a Hitachi M-80 spectrometer (Hitachi Ltd., Tokyo). Infrared (IR) spectra were recorded with a JASCO A-202 spectrophotometer (Japan Spectroscopic Co., Ltd., Tokyo).

HPLC was carried out on a Shimadzu LC-6A chromatograph equipped with a Shimadzu SPD-6AV UV (240 nm)(Shimadzu Co., Ltd., Kyoto, Japan) or a Hitachi F-1050 fluorescence detector (Ex $270 \mathrm{~nm}, \mathrm{Em}$ $370 \mathrm{~nm})$ was used. A YMC-GEL C 8 -120-S5 $(5 \mu \mathrm{m})$ column $(15 \mathrm{~cm} \times 0.46 \mathrm{~cm}$ i.d.)(YMC Co., Kyoto) was used with $\mathrm{CH}_{3} \mathrm{CN}$ as a mobile phase under an ambient temperature at a flow rate of $1 \mathrm{ml} / \mathrm{min}$.

\section{Synthesis of 4-(1-pyrenyl)-1,2,4-triazoline-3,5-dione (V)}

The compound was synthesized according to a procedure described by Cookson et al. ${ }^{7}$ Pyrene-1carbonyl azide $(I)^{8}(765 \mathrm{mg})$ in toluene $(15 \mathrm{ml})$, prepared from pyrene-1-carboxaldehyde via pyrene-1-carboxylic acid $^{9}$, was heated at $100^{\circ} \mathrm{C}$ to give pyrene-1-isocyanate (II). The reaction mixture was added to a solution of carbazic acid ethyl ester ( $308 \mathrm{mg}$ ) in benzene $(15 \mathrm{ml})$ under ice-cooling. The reaction mixture was kept at room temperature for $1 \mathrm{~h}$ and then at $100^{\circ} \mathrm{C}$ for $1 \mathrm{~h}$. After filtration, the obtained precipitate was washed with benzene and dried in vacuo to give 4-(1-pyrenyl)-1carbethoxysemicarbazide (III) as a colorless amorphous substance $(803 \mathrm{mg}) . \mathrm{mp}>300^{\circ} \mathrm{C}$. IR $\nu_{\max }^{\mathrm{KBr}} \mathrm{cm}^{-1}: 3275$, $1720,1650,1570 .{ }^{10}{ }^{1} \mathrm{H}-\mathrm{NMR}$ (DMSO-d $) \delta: 1.24(3 \mathrm{H}$, $\left.\mathrm{t}, J=7.1 \mathrm{~Hz},-\mathrm{CH}_{3}\right), 4.11\left(2 \mathrm{H}, \mathrm{q}, J=7.1 \mathrm{~Hz},-\mathrm{CH}_{2-}\right)$, $7.70-8.40$ (9H, m, pyrene-H). MS $m / z: 347\left(\mathrm{M}^{+}\right)$. A suspension of III ( $475 \mathrm{mg})$ was treated with $4 \mathrm{M} \mathrm{KOH}$ $(7 \mathrm{ml})$ at $80^{\circ} \mathrm{C}$ for $1.5 \mathrm{~h}$. The reaction mixture was acidified with conc. $\mathrm{HCl}$, and the obtained precipitate was collected, washed with $\mathrm{H}_{2} \mathrm{O}$ and dried in vacuo. The product was reprecipitated from dimethylformamide- $\mathrm{H}_{2} \mathrm{O}$ to give 4-(1-pyrenyl)urazole (IV) as a colorless amorphous substance $(377 \mathrm{mg}) . \mathrm{mp}>300^{\circ} \mathrm{C}$. IR $\nu_{\max }^{\mathrm{KBr}} \mathrm{cm}^{-1}: 3050,1665,1460 .{ }^{10} \mathrm{MS} \mathrm{m} / z: 301\left(\mathrm{M}^{+}\right)$. $t$-Butyl hypochlorite $(8.2 \mu \mathrm{l}: 69 \mu \mathrm{mol})$ was added to the suspension of IV (19.5 mg: $65 \mu \mathrm{mol})$ in AcOEt $(5 \mathrm{ml})$ under an $\mathrm{N}_{2}$ gas stream, and the reaction mixture was 

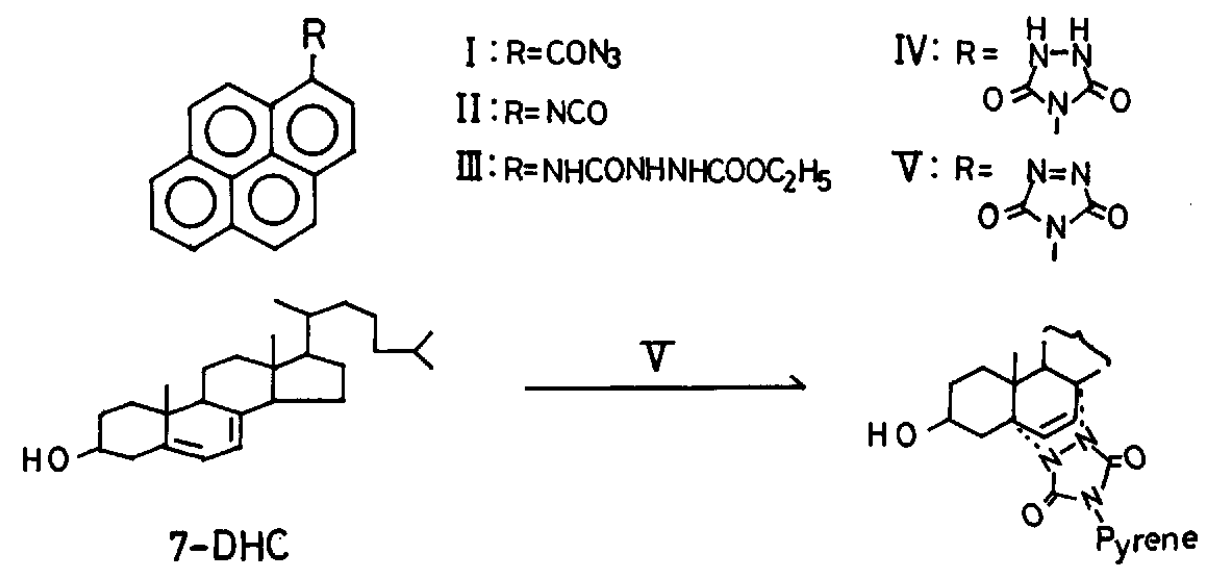

Fig. 1 Structures of the derivatization reagent, its synthetic intermediates and a derivatization reaction with 7-dehydrocholesterol.

stirred for $6 \mathrm{~h}$ at room temperature. The mixture was centrifuged to remove any unreacted IV; a dark-red supernatant containing 4-(1-pyrenyl)-1,2,4-triazoline-3,5dione (V) was used for the derivatization. The solution was stable for at least $7 \mathrm{~d}$ in a refrigerator, which was confirmed by measuring the intensity of the UV absorption $\left(\lambda_{\max }^{A} 537 \mathrm{~nm}\right){ }^{10}$ After evaporation of the solvent, $\mathbf{V}$ was obtained as a dark-red amorphous substance $(15 \mathrm{mg}) . \mathrm{mp}>300^{\circ} \mathrm{C}$. MS $m / z: 299\left(\mathrm{M}^{+}\right) .{ }^{11}$

\section{Preparation of the authentic 7-dehydrocholesterol deriva- tive}

A solution of $\mathbf{V}$ in AcOEt was added to a solution of 7-DHC (12.5 mg) in AcOEt $(2 \mathrm{ml})$ at room temperature until the red color of the excess reagent remained in the reaction mixture. The mixture was washed with $1 \mathrm{M}$ $\mathrm{NaOH}$, then $\mathrm{H}_{2} \mathrm{O}$, and finally dried over anhydrous $\mathrm{Na}_{2} \mathrm{SO}_{4}$ and evaporated in vacuo. The residue obtained was twice subjected to preparative thin-layer chromatography using benzene-AcOEt $\left(3: 2 ; R_{f} 0.40\right)$ and then $\mathrm{CHCl}_{3}-\mathrm{MeOH}\left(100: 2 ; R_{\mathrm{f}} \mathbf{0 . 3 0}\right)$ as a developing solvent. The corresponding spot was eluted with AcOEt to give the desired adduct as a pale-yellow solid $(14.3 \mathrm{mg}) .{ }^{1} \mathrm{H}$ $\operatorname{NMR}\left(\mathrm{CDCl}_{3}\right) \delta: 0.80$ and 0.87 (each $3 \mathrm{H}$, each s, 18- or $\left.19-\mathrm{CH}_{3}\right), 3.14(1 \mathrm{H}, \mathrm{dd}, \mathrm{J}=2.9,14.3 \mathrm{~Hz}, 9 \alpha-\mathrm{H}), 4.36(1 \mathrm{H}$, br s, $3 \alpha-\mathrm{H}$ ), 6.14 and 6.33 (each $1 \mathrm{H}$, each dd, $J=8.6$, $2.3 \mathrm{~Hz}, 6-$ or $7-\mathrm{H}), 7.60-8.30$ (9H, m, pyrene-H).

\section{Results and Discussion}

The design of a promising derivatization reagent requires structural features having both a group sensitive to a detector and functional group reactive toward the diene moiety. 4-Phenyl-1,2,4-triazoline-3,5dione, a Cookson reagent ${ }^{7}$, has been used as a protecting group of the diene moiety for the synthesis of $\mathrm{VD}_{3}$-related compounds. ${ }^{12}$ The reagent gave a stable Diels-Alder adduct quantitatively under mild condi- tions within a short time. These data prompted us to develop a derivatization reagent possessing pyrene and triazolinedione as a chromophore or fluorophore and a reacting group, respectively.

The desired derivatization reagent, 4-(1-pyrenyl)1,2,4-triazoline-3,5-dione (V), was synthesized from pyrene-1-carbonyl azide (I) according to a known method. ${ }^{7}$ The reactivity of $\mathrm{V}(260 \mathrm{nmol} / \mathrm{ml})$ was then investigated with 7-DHC $(13 \mathrm{nmol} / \mathrm{ml})$ in ethyl acetate under ice-cooling (Fig. 1). An aliquot of the resulting solution was applied to HPLC. The reaction rate was estimated by a comparison with the peak area of the standard derivative. Under the above-mentioned condition derivatization was completed within $5 \mathrm{~min}$. The resulting adduct was responsive to both $\mathrm{UV}$ and fluorescence detectors with a detection limit of $30 \mathrm{fmol}$ and $2.4 \mathrm{pmol}\left(t_{\mathrm{R}}=5.0 \mathrm{~min}\right.$ : at signal to noise ratio $\left.=5\right)$, respectively. The adduct was stable at room temperature for at least $1 \mathrm{~d}$.

The newly developed derivatization reagent having a dienophile for HPLC has proved to be satisfactory with respect to reactivity. The sensitivity of the adduct using the UV detector is much higher than that obtained with the fluorescence detector, the details of which are now under investigation in our laboratories. The use of this type of reagent is promising for the selective labeling of the cisoid diene moiety in 7-DHC, $\mathrm{VD}_{3}$ and related compounds. The synthesis of this type of reagent having another chromophore or fluorophore and the application of the present method to the determination of bio-active substances in biological fluids will be presented in a future communication.

The work was supported in part by a grant from the Ministry of Education, Science and Culture of Japan. 


\section{References and Notes}

1. This paper is dedicated to Professor Toshio Nambara (Tohoku University, Sendai, Japan) on the occassion of his retirement.

2. H. F. DeLuca, "Handbook of Lipid Research", ed. H. F. DeLuca, Vol. 2, p. 69, Plenum Press, New York, London, 1978.

3. K. Takada, T. Okano, Y. Tamura, S. Matsui and T. Kobayashi, J. Nutr. Sci. Vitaminol, 25, 385 (1979).

4. J. Maclaughlin and M. F. Holick, J. Clin. Invest., 76, 1536 (1985).

5. T. Iwata, H. Hanazono, M. Yamaguchi, M. Nakamura and Y. Ohkura, J. Chromatogr., 491,404 (1989).

6. T. Iwata, H. Hanazono, M. Yamaguchi, M. Nakamura and Y. Ohkura, Anal. Sci, 5, 671 (1989).

7. R. C. Cookson, S. S. Gupte, I. D. R. Stevens and C. T.
Watts, Org. Syn., 51, 121 (1971)

8. H. Fujino, M. Takeda and S. Goya, Meeting of Kyushu Branch, Pharmaceutical Society of Japan, Nagasaki, December 1989.

9. H. Reimlinger, J.-P. Golstein, J. Jadot and P. Jung, Chem. Ber., 97, 349 (1964).

10. M. E. Burrage, R. C. Cookson, S. S. Gupte and I. D. R. Stevens, J. Chem. Soc., Perkin Trans. 2, 1975, 1325.

11. The compounds III and IV gave the satisfactory elemental analyses. The details of the synthesis and properties of $\mathbf{V}$ will be reported elsewhere in the near future.

12. D. H. R. Barton, T. Shioiri and D. A. Widdowson, Chem. Commun., 1970, 939.

(Received January 29, 1990) (Accepted March 1, 1990) 